\title{
OS ASPECTOS FILOSÓFICOS, SOCIOLÓGICOS E PEDAGÓGICOS E OS CAMPOS DE EXPERIÊNCIAS DA BNCC
}

\author{
PHILOSOPHICAL, SOCIOLOGICAL AND PEDAGOGICAL ASPECTS AND BNCC EXPERIENCE \\ FIELDS
}

Cênea Alves de Sene

Prefeitura Municipal de Barra do Bugres, Mato Grosso, MT, Brasil. E-mail: cenea.sene2@gmail.com

\section{Najela Aparecida de Oliveira}

Prefeitura Municipal de Barra do Bugres, Mato Grosso, MT, Brasil. E-mail: najelaoliveira15@gmail.com

\section{Patrícia Ramos Aguiar}

Prefeitura Municipal de Barra do Bugres, Mato Grosso, MT, Brasil.E-mail: patricia_e_aguiar@hotmail.com

DOI: https://doi.org/10.46550/amormundi.v2i8.137

Recebido em: 18.11.2021

Aceito em: 31.12.2021

\begin{abstract}
Resumo: O presente artigo traz uma breve análise a respeito da Base Nacional Comum Curricular frente aos aspectos sociológicos, filosóficos e pedagógicos. Assim, esse artigo demonstra a importância da inserção desses aspectos na organização das práticas pedagógicas na etapa da educação Infantil, uma vez que, nessa fase se faz imprescindível desenvolver no educando uma concepção acerca dos elementos sociais formativos. Logo, buscou-se pontuar os principais aspectos que caracterizam o processo de construção e desenvolvimento intelectual do indivíduo ainda na primeira infância. E, para isso, utilizouse como norte a Base Nacional Comum Curricular (BNCC) que prevê os campos de experiências que atualmente compóem todo o processo de educacional do aluno, bem como as competências e habilidades que o mesmo deverá desenvolver em cada etapa da educação básica nacional. O objetivo principal desse artigo é considerar a relação entre os aspectos formativos e suas contribuiçôes para o processo de ensinoaprendizagem da perspectiva didático-pedagógica traçada pela BNCC. E, a partir da reflexão proposta por meio da pesquisa bibliográfica desenvolvida, é possível concluir que os aspectos sociológicos, filosóficos e pedagógicos são medidas imprescindíveis no processo de construção do conhecimento da criança.
\end{abstract}

Palavras-chave: Aspectos formativos. Base Nacional Comum Curricular. Campos de experi-ências.

Abstract: This article provides a brief analysis of the Common National Curriculum Base in view of sociological, philosophical and pedagogical aspects. Thus, this article demonstrates the importance of inserting these aspects in the organization of pedagogical practices in the stage of early childhood education, since, at this stage, it is essential to develop a conception of the educational social elements in the student. Therefore, we sought to point out the main aspects that characterize the process of construction and intellectual development of the individual in early childhood. And, for this, the Common National Curriculum Base (BNCC) was used as a guideline, which provides for the fields of experience that currently make up the entire student educational process, as well as the skills and abilities that helshe should develop at each stage of the national 
basic education. The main objective of this article is to consider the relationship between the formative aspects and their contributions to the teaching-learning process from the didactic-pedagogical perspective outlined by the BNCC. And, from the proposed reflection through the developed bibliographical research, it is possible to conclude that the sociological, philosophical and pedagogical aspects are essential measures in the process of construction of the child's knowledge.

Keywords: Teacher Training. Theories and Pedagogical Conceptions. Learn Formative aspects. Common National Curriculum Base. Fields of experience.ing.

\section{Introduçáo}

Tnicialmente, faz-se necessário compreender a Base Nacional Comum Curricular (BNCC) como um documento mandatório que estabelece os padróes de ensino que as redes públicas e privadas precisam se basear na concepçáo de seus currículos escolares. Como um todo, esse documento prevê as habilidades e competências que cada grupo de estudante precisa desenvolver ao final de cada ciclo das etapas da educação (educaçáo infantil, ensino fundamental e ensino médio).

Acerca da sua relevância, a BNCC obrigatoriamente passou a integrar todos os planos escolares até meados do ano 2020, promovendo a homogeneidade na educação nacional, além do pleno acesso e permanência do estudante em sala de aula. Nesse sentido, como documento norteador, a BNCC traz alguns elementos fundamentais em sua composição a fim de possibilitar o desenvolvimento integral do aluno, como os campos de experiências, competências e habilidades.

Com relação a educação infantil, percebe-se que é uma das etapas da educação básica que mais sofreu alteraçóes em sua proposta, uma vez que surgiram novas concepçóes acerca das potencialidades e desenvolvimento de uma criança, passando a ser considerada como indivíduo com identidade pessoal e histórica. Isso significa que a criança passou a exercer um papel de influência na sociedade, sendo percebida como um investimento futuro por parte da própria sociedade, passou a ter voz e a ter suas necessidades como prioridade.

Desse modo, a Base Nacional Comum Curricular dá ênfase à essa nova concepção sobre a criança e, com isso, estabelece uma série de medidas que potencializam as açóes pedagógicas a fim de se explorar a plena capacidade de um indivíduo na infância. Nesse momento, cabe mencionar, a exploração que a BNCC propóe quanto aos aspectos filosóficos, sociológicos e pedagógicos na educação infantil, incentivando reflexôes sobre a organização do trabalho pedagógico nessa fase, tendo em vista oportunizar açóes que favoreçam a articulação dos conhecimentos advindos da convivência extraescolar com aqueles sistematizados na escola, nomeados por científicos.

Portanto, este artigo científico cuja temática é os aspectos filosóficos, sociológicos e pedagógicos e os campos de experiências da BNCC tem por objetivo considerar a relação entre esses aspectos e suas contribuiçóes para o processo de ensino-aprendizagem da perspectiva didático-pedagógica traçada pela BNCC.

\section{Metodologia}

$\mathrm{Na}$ pesquisa descritiva "se observam, registram, analisam, classificam e interpretam os fatos, sem que haja interferência por parte do pesquisador" (PRESTES, 2003, p. 26). Esse tipo 
de pesquisa tem por premissa analisar, com base na teoria, quais são as possíveis práticas que podem amenizar a problemática do estudo apenas por meio da observação, análise e descriçóes objetivas. Assim, considerando as características dos métodos de estudo, o presente artigo é de caráter descritivo, uma vez que busca observar, registrar, interpretar e discutir a temática à luz da teoria.

No que se refere aos meios, Lakatos (2010) assevera que os métodos de procedimento de uma pesquisa podem possuir diversas características de investigação, entre elas, a pesquisa bibliográfica e pesquisa de campo. Com respeito à pesquisa bibliográfica, CERVO; BERVIAN (1996, p. 48) descrevem-na como "a pesquisa que procura explicar um problema a partir de referências teóricas publicadas em obras científicas", e que neste caso serão baseadas em obras sobre os aspectos sociológicos, filosóficos e pedagógicos e os campos de experiências apresentados pela Base Nacional Comum Curricular.

Vergara (2007), refere-se ainda a pesquisa como a coleta de informaçóes para um estudo sistematizado desenvolvido com base no levantamento de material publicado em livros, revistas, jornais ou sites. Logo, a metodologia utilizada nessa proposta corresponde à pesquisa bibliográfica por conta da fundamentação teórica que se apresenta. Finalmente, a metodologia adotou ainda, a abordagem qualitativa, a qual tratou de considerar o que a teoria apresenta acerca do tema da pesquisa. O levantamento de informaçóes e desenvolvimento do artigo aconteceu entre os meses de dezembro de 2021 e janeiro de 2022.

\section{Referencial teórico}

\subsection{Aspectos sociológicos, filosóficos e pedagógicos na educaçáo infantil}

A Base Nacional Comum Curricular (BNCC) constitui-se como um referencial para a construção e efetivação dos currículos escolares, uma vez que por meio desse documento são apresentadas as aprendizagens essenciais a serem promovidas, de maneira adequada à realidade de cada sistema ou rede de ensino e instituição escolar. Assim, a BNCC é o documento que aponta quais aspectos devem ser promovidos na formação e no desenvolvimento humano global dos alunos, para que sejam capazes de construir uma sociedade mais justa, ética, democrática, responsável, inclusiva, sustentável e solidária.

Logo, o objetivo deste documento é orientar para uma concepção de Educação Integral, que não se refere ao tempo de permanência do estudante no espaço escolar ou a uma determinada modalidade de escola. Nesse sentido, a educação integral indica promoção do desenvolvimento de crianças e jovens em todas as suas dimensóes: intelectual, física, emocional, social e cultural. Esse direcionamento implica que, além dos aspectos acadêmicos, precisa-se expandir a capacidade dos alunos de lidar com seu corpo e bem-estar, suas emoçóes e relaçóes, sua atuação profissional e cidadã e sua identidade e repertório cultural.

Segundo a Lei de Diretrizes e Bases da Educação Nacional (Lei 9394/96), essa etapa da educação infantil é de grande importância para a criança por constituir as primeiras açóes educativas fora do contexto familiar. Assim, é possível afirmar que essa etapa da educação básica tem por finalidade promover o desenvolvimento integral do aluno por meio de espaços, tempos e estratégias que favoreçam sua aprendizagem e desenvolvimento. Considerando o 
exposto, no artigo 29 da Lei 9.394/96, alicerçada na Constituição Federal de 1988, prevê que a educação infantil deve estimular o desenvolvimento cognitivo dos alunos, tendo por intenção o desenvolvimento de diversos aspectos que complementam a formação do indivíduo, dentre esses, os aspectos sociológicos, filosóficos e pedagógicos.

Sobre isso, Duarte e Batista (2013) afirmam que, os aspectos sociológicos estáo relacionados em como a educação infantil reflete no processo de formação das crianças, percebendo as demandas sociais e culturais da sociedade com respeito ao sistema educacional. $\mathrm{O}$ conhecimento, atitudes e valores que são considerados necessários para o processo de socialização dos alunos. Com relação aos aspectos filosóficos, Andrade (2010) diz que é por meio desse aspecto que os alunos são conduzidos aos questionamentos acerca de uma ação e a compreensão de um processo, mesmo ainda na educação infantil. Em outras palavras, se diz que os aspectos filosóficos são determinantes quanto a compreensão do comportamento humano e as açôes de contínua reflexão.

Para Duarte e Batista (2013), os aspectos pedagógicos referem-se aos modelos pedagógicos relacionados às abordagens atuais da educaçáo infantil e que, orientam o processo educacional das crianças nas escolas, bem como as metodologias de ensino utilizadas pelos professores durante o processo de ensino-aprendizagem. Assim, é possível concluir que os aspectos sociológicos, filosóficos e pedagógicos da educação infantil são diferentes fontes que colaboram para o processo de desenvolvimento integral dos alunos em coerência com a abordagem educacional na primeira infância.

\subsection{Os campos de experiência}

Os campos de experiências são trazidos pela Base Nacional Comum Curricular propondo uma nova organização curricular, na qual a criança é o centro do processo educativo. De acordo com a BNCC (2018), os cinco campos de experiências para a educação infantil indicam quais são as noçóes, habilidades, atitudes, valores e afetos que as crianças devem desenvolver dos 0 aos 5 anos e 11 meses de idade, buscando garantir os direitos de aprendizagem das crianças. Nesse contexto, Pinto (2018) explicita os campos de experiências como "um arranjo curricular que acolhe as situaçôes e as experiências da vida cotidiana da criança e seus saberes, entrelaçando-os aos conhecimentos que fazem parte de um patrimônio cultural.

Assim, os campos de experiências estão organizados de forma a apoiar o corpo docente no planejamento de sua prática intencional, buscando romper com uma organização disciplinar de conteúdos e propor uma articulação da produção dos saberes. Considerando que as atividades propostas à criança devem ser bem planejadas, proporcionando à mesma tempo e espaço para se expressar, de modo único e pessoal.

A educação, como muitos outros aspectos da vida, está em constante evolução. Frente a isso, os campos de experiências da BNCC buscam priorizar o desenvolvimento infantil de maneira holística. Estabelecendo direitos à aprendizagem e campos de experiências que reportam à uma nova maneira de organizaçáo do ensino, uma vez que partindo dessa nova concepção educacional, o aluno é o centro do processo educativo. Por isso, os campos de experiências devem nortear e apoiar o planejamento pedagógico dos docentes, garantindo que o aluno tenha espaço, tempo e liberdade para se expressar e, em contrapartida, o educador possa acompanhá-lo nessa trajetória. 
Inicialmente, cada campo tem objetivos de aprendizagem e desenvolvimento, garantindo acesso às competências gerais estipuladas pelo documento, tornando o cenário educacional mais justo e igualitário em todo o país. Esses campos são, portanto, as vivências pelas quais as crianças poderão interagir e se expressar, convivendo com situaçóes que permitam a elas explorar, pesquisar, imaginar e movimentar-se. No que se refere à educação infantil, o processo de aprendizagem se desdobra e articula-se em seis direitos básicos: conviver, expressar-se, brincar, participar, explorar e conhecer.

Portanto, os campos de experiências propostos pela Base Nacional Comum Curricular (2018) são distribuídos em cinco eixos temáticos, sendo: "O eu, o outro e o nós"; "corpo, gestos e movimentos"; "traços, sons, cores e formas"; "escuta, fala, pensamento e imaginação" e "espaço, tempo, quantidades, relaçôes e transformaçôes". Em suma, tais campos visam garantir experiências que promovam o conhecimento de si e do mundo; favoreçam a imersão das crianças no universo das linguagens; ampliem a confiança e participação dos alunos; possibilitem autonomia no processo de aprendizagem; explorem a curiosidade e interação coletiva.

Há ainda alguns apontamentos interessantes quanto aos campos de experiências e a sua proposta no contexto da educação infantil. A princípio, dentro dos campos, há objetivos de aprendizagem que são divididos em três grupos etários (bebês, crianças bem pequenas e crianças pequenas). Cada grupo possui habilidades que devem ser exploradas durante o processo de construção de conhecimento, estando essas, evidentes nos planejamentos pedagógicos, que por sua vez precisam pautar-se nos referidos campos de experiências.

\subsubsection{O eu, o outro e o nós}

O primeiro campo de experiência trazido pela BNCC é "O eu, o outro e o nós" cuja finalidade é demonstrar que a criança, na interação com os pares e com adultos, vão constituindo um modo próprio de agir, sentir e pensar e descobrem a existência de outros modos de vida, com múltiplos conceitos. Assim, ao mesmo tempo em que participam de relaçôes sociais e de cuidados pessoais, as crianças constroem autonomia, senso de autocuidado, reciprocidade e de interdependência com o meio.

Considerando Menezes (2018), os principais direitos de aprendizagem presentes neste campo de experiência são: conviver, brincar e explorar, uma vez que, a convivência múltipla proporciona a interação com diferentes grupos; o brincar coletivo cria a consciência de respeito, zelo e solidariedade pelo outro e, ainda, o explorar amplia a noção de mundo e a sensibilidade da criança.

De modo geral, a BNCC (2018) descreve que é na interação entre os pares e com os adultos que as crianças constituem seu modo de agir, sentir e pensar; descobrem as pluralidades do universo social e participam das suas primeiras experiências sociais, possibilitando a construção de percepçóes e questionamentos sobre si e sobre os outros, além de perceber-se como indivíduo pertencente a um grupo social. E, por meio dessas experiências, as crianças passam a valorizar sua identidade, respeitar a coletividade e reconhecer as diferenças que formam os indivíduos.

Mendes (2018) ainda comenta que o campo de experiência "O eu, o outro e o nós" compreende que os direitos das crianças precisam ser assegurados desde a organizaçáo dos ambientes educativos, do espaço e tempo, de modo a promover oportunidades de se conhecer e se relacionar autonomamente. Assim, a construção da identidade (eu) pela criança é fundamental 
para o seu desenvolvimento e acontece ao longo da vida. Em contrapartida, é imprescindível possibilitar à criança o relacionamento coletivo (o outro), ampliando a confiança e a participaçáo dos alunos nas diversas propostas pedagógicas (o nós).

Portanto, percebe-se que esse campo de experiência busca apresentar conceitos que ampliem o olhar das crianças para a existência de outros ambientes sociais, outras culturas, lugares e costumes diferentes dos seus. Envolvendo ainda noçóes de equidade, respeito e valorização dos demais indivíduos.

\subsubsection{Corpo, gestos e movimentos}

O campo "corpo, gestos e movimentos" destaca experiências ricas e diversificadas em que gestos, mímicas, posturas e movimentos expressivos compóem uma linguagem corporal com a qual as crianças se expressam, se comunicam e constroem conhecimentos sobre si e sobre o universo social e cultural. Para Menezes (2018), os movimentos corporais (tato, os gestos, as posturas, os deslocamentos, entre outros) representam um recurso para a criança perceber, expressar emoçôes, reconhecer sensaçôes, interagir, brincar, ocupar espaços e neles se localizar, construindo conhecimento.

Desse modo, a BNCC (2018) aponta que na etapa da educação infantil, o campo "corpo, gestos e movimentos" ganha centralidade, uma vez que por meio dele as crianças conhecem e reconhecem as sensações e funçóes de seu corpo, identificam suas potencialidades e seus limites, desenvolvendo, ao mesmo tempo, a consciência sobre o que é seguro e o que pode ser um risco à sua integridade física.

Diante disso, percebe-se que com o corpo as crianças exploram o seu meio, estabelecem relaçóes de contato com o outro, expressam-se, brincam e intensificam o conhecimento sobre si mesmas e sobre o universo social e cultural da qual fazem parte. Na educação infantil, esse campo de experiência ganha destaque, já que os alunos desenvolvem autonomia na utilização dos movimentos para experimentar novas possibilidades de exploração.

De acordo com Pinto (2018), as primeiras formas de comunicação da criança são pelo corpo; por meio da linguagem corporal as crianças expressam emoçóes, frustraçóes, desconfortos, desejos e conquistas. Isso dá a entender que, através do movimento a criança estabelece o diálogo com o ambiente humano, construindo o seu jeito próprio de pertencimento a esse meio. Além disso, esse campo de experiência abre diversas possibilidades de exploração corporal, contribuindo para o desenvolvimento da força e ritmo da criança.

\footnotetext{
A criança na sua integralidade, conhece e explora o mundo por meio da linguagem corporal, sendo manifestada mediante aos gestos, expressóes faciais, mímicas, deslocamentos espaciais, manipulação e exploração dos objetos, das brincadeiras e da sua cultura, expressando suas vontades e emoçóes, vivenciando diferentes experiências em relação ao gênero, a etnia, classe, religião e a sexualidade (MENDES, 2018, p. 33).
}

Portanto, compreende-se que, na educação infantil, o corpo é o ponto de partida para o desenvolvimento da criança, isso porque por meio da estimulação e desafios corporais, o estudante irá apropriar-se dos seus sentidos e funções, ampliando seu repertório de gestos, a emancipação e a liberdade corporal. Com isso, conclui-se que, esse campo possibilita diversas vivencias com o corpo, na qual a criança estabelece inúmeras relaçóes e apropriação da sua consciência corporal. 


\subsubsection{Traços, sons, cores e formas}

$\mathrm{Na}$ apresentação do campo de experiência "traços, sons, cores e formas", a Base Nacional Comum Curricular (2018) contextualiza que uma maneira de atender à necessidade da criança de sentir o mundo e a si própria é imergi-la em um ambiente diversificado em termos visuais e sonoros e garantir que tenham experiências com a música, a pintura, a escultura e outras formas artísticas, como a dança, a literatura e o teatro. Assim, apropriando-se das linguagens básicas dessas expressôes da criação humana, ela amplia sua vivência estética, desenvolvendo a sensibilidade, criatividade e expressão pessoal, afirmando sua singularidade e reconstruindo a cultura.

Portanto, percebe-se que nesse campo o destaque recai sobre as experiências voltadas para a expressividade das crianças no âmbito das artes visuais, teatrais, musicais e literárias. Em outras palavras, Menezes (2018) diz que o foco desse campo é dar oportunidade para a criança viver de maneira criativa, com experiências diversas que explorem suas potencialidades artísticas.

Por isso, Delmondes e Silva (2018) comenta que a educação infantil precisa promover a participação das crianças em tempos e espaços para a produção, manifestação e apreciação artística, favorecendo o desenvolvimento da sensibilidade, da criatividade e da expressão pessoal das crianças, permitindo que se apropriem e reconfigurem, permanentemente, a cultura e potencializem suas singularidades, ao ampliar repertórios e interpretar suas experiências e vivências artísticas.

Ademais, Pinto (2018) diz que, das inúmeras maneiras de os seres humanos se expressarem reconhece-se que as artes visuais, a música, a dança e o teatro são formas de linguagens e expressôes. E, ao mesmo tempo em que intensifica a comunicaçáo, o campo de experiência traços, sons, cores e formas mobilizam o desenvolvimento de diferentes sensaçôes, emoções e aprendizagens, bem como, ampliar a produção, manifestação e apreciação criativa, permitindo que o aluno amplie seus repertórios e vivências artísticas.

Todavia, cabe trazer à discussão, que esse campo não tem por finalidade a formação de artistas. Conforme Mendes (2018) menciona, o campo de experiência traços, sons, cores e formas visa auxiliar, por meio da arte, na formação de crianças sensíveis ao mundo, capazes de expressar sensaçóes, sentimentos, pensamentos e de elaborar seus próprios percursos criativos, articulando a percepção, a sensibilidade, a imaginação e a cognição.

Portanto, é possível afirmar que o trabalho nesse campo deve permitir a imersão das crianças nas diferentes linguagens artísticas e o progressivo domínio por elas de expressóes gestual, verbal, musical entre outras, sempre considerando que é por meio dessas linguagens e expressóes que a criança passa a perceber-se como ser autônomo e capaz de proporcionar a si mesmo inúmeros conhecimentos.

\subsubsection{Escuta, fala, pensamento e imaginação}

Segundo Delmondes e Silva (2018), a BNCC propóe que, ao longo da trajetória na educaçáo infantil, as crianças construam conhecimentos a respeito das linguagens oral e escrita por meio de gestos, expressóes, sons da língua, rimas, leitura de imagens e letras, identificação de palavras em poesias, parlendas, cançôes e também a partir da escuta e dramatização de histórias e da participação na produção de textos escritos. 
Assim, o quarto campo de experiência apresentado pelo documento mandatório é "escuta, fala, pensamento e imaginaçâa", o qual representa a apropriação das habilidades de falar, ler e escrever, inicialmente empregado pelos gestos e, mais tarde, pela oralidade e escrita. Além disso, Mendes (2018) afirma que, esse campo de experiência tem por finalidade garantir à criança: tempo para falar, ouvir, escutar, brincar, comer, descansar e imergir no universo literário por meio de história lidas/ouvidas e através da escrita.

\subsubsection{Espaços, tempos, quantidades, relaçóes e transformaçóes}

O último campo de experiência apresentado pela BNCC é "espaços, tempos, quantidades, relaçôes e transformaçôes", que objetiva oferecer às crianças oportunidades para investigar as muitas questôes que vão formulando acerca do mundo e de si mesmas. Para Menezes (2018), é por meio deste campo que se torna possível motivar as crianças a ter um olhar crítico e criativo sobre o mundo, promovendo aprendizagens mais significativas e reflexivas.

Assim, nesse campo de experiências as crianças demonstram interesse e curiosidade nas situaçôes de criação de cenários, narrativas de histórias e descobertas quanto a situações cotidianas. E a criança em sua atuação protagonista, busca compreender o funcionamento dos elementos que a cercam, realizando inúmeras indagaçóes frente às vivencias. Em outras palavras, esse campo de promove experiências que desenvolvem capacidades de levantar hipóteses e buscar informaçóes por meio de suas interaçóes.

Por fim, a BNCC (2018) salienta que, através desse campo, a educação infantil precisa promover experiências nas quais as crianças possam fazer observações, manipular objetos, investigar e explorar seu entorno, levantar hipóteses e consultar fontes de informaçáo para buscar respostas às suas curiosidades e indagaçóes.

\section{Consideraçóes finais}

Durante o desenvolvimento deste artigo, percebeu-se que os aspectos sociológicos, filosóficos e pedagógicos são medidas imprescindíveis no processo de construção do conhecimento da criança. E, além de tal importância, cabe ressaltar que essa vertente do conhecimento se propóe como base para o desenvolvimento intelectual do indivíduo. E assim, por meio de constantes incentivos, o educando constrói por si mesmo sua visão crítica acerca da sociedade.

Relacionando tais aspectos à prática em sala de aula, se faz necessário uma abordagem além da rotina educacional, pois, é nesse momento que as percepçóes da criança podem/devem ser instigadas a ponto de gerar o anseio, entusiasmo e interesse pela exploraçáo e descobertas. Nesse contexto, compreende-se com maior propriedade a função que os campos de experiências desempenham durante a fase de construção do conhecimento - a educação infantil. Isso se dá porque tais campos de experiências priorizam o pleno desenvolvimento integral do aluno, explorando suas possibilidades e descobertas.

\section{Referências}

ANDRADE, Lucimary Bernabé Pedrosa de. Educaçáo infantil: discurso, legislação e práticas educacionais. São Paulo: Cultura Acadêmica, 2010. 
BRASIL, Ministério da Educação. Base Nacional Comum Curricular. Disponível em: < http://basenacionalcomum.mec.gov.br/>. Acesso em: 05, jan, 2022.

BRASIL. Ministério da Educação. Lei de Diretrizes e Bases da Educaçáo Nacional. Disponível em: <http://www.planalto.gov.br/ccivil_03/Leis/L9394.htm>. Acesso em: 05, jan, 2022.

CERVO, A. L; BERVIAN, P. A. Metodologia científica. São Paulo: Makron Books, 1996.

DELMONDES, Marina de Oliveira; SILVA, Tamili Mardegan da. Os Campos de Experiências na Base Nacional Comum Curricular. Disponível em: <https://revistas.ufpi.br/ index.php/lingedusoc/article/viewFile/7693/pdf>. Acesso em: 05, jan, 2022.

DUARTE, Bruna da Silva; BATISTA, Cleide Vitor Mussini. Desenvolvimento Infantil: Importância das Atividades Operacionais na Educação Infantil. Disponível: <http://www. uel.br/eventos/semanaeducacao/pages/arquivos/ANAIS/ARTIGO/SABERES\%20E\%20 PRATICAS/DESENVOLVIMENTO\%20INFANTIL.pdf>. Acesso em: 05, jan, 2022.

LAKATOS, E. M. Fundamentos de metodologia científica. 5. ed. São Paulo: Atlas, 2007.

MENDES, Brígida Couto. Proposta Curricular para Território Mato-grossense: Educaçáo Infantil. Cuiabá: SEDUC, 2018.

MENEZES, Pedro. Jogos e brincadeiras. Disponível em: <https://www.todamateria. com.br/jogos-e brincadeiras/\#: : :text=Jogos $\% 20 \mathrm{e} \% 20$ brincadeiras $\% 20 \mathrm{~s} \% \mathrm{C} 3 \% \mathrm{~A} 3 \mathrm{o} \% 20$ atividades,a\%20resolu\%C3\%A7\%C3\%A3o\%20das\%20tarefas\%20propostas. >. Acesso em: 05, jan, 2022.

PINTO, A. Cadê? Achou! Educar, cuidar e brincar na ação pedagógica da creche. Curitiba: Positivo, 2018.

PRESTES, Maria Luci de Mesquita. A pesquisa e a construçáo do conhecimento científico: do planejamento aos textos, da escola à academia. 2. ed. rev e atual. e ampl. Sáo Paulo: Rêspel, 2003.

VERGARA, Sylvia Constant. Projetos e Relatórios de Pesquisa em Administraçáo. São Paulo: Atlas, 2007. 